\title{
Fabrication of Metallic Lines by Aerosol Jet Printing: Study of the Effect of Substrate Temperature on the Aspect Ratio
}

\section{ALEXEY ANATOLEVICH EFIMOV ${ }^{1 *}$, PAVEL VLADIMIROVICH ARSENOV ${ }^{1}$, KIRILL NIKOLAEVICH MINKOV ${ }^{2}$ and VICTOR VLADIMIROVICH IVANOV ${ }^{1}$}

\author{
'Department of Physical and Quantum Electronics, Moscow Institute of Physics and Technology, \\ Dolgoprudny 141701, Russia. \\ ${ }^{2}$ Moscow Institute of Electronics and Mathematics, National Research University of Higher School \\ of Economics, Moscow 123458, Russia. \\ ${ }^{*}$ Corresponding author E-mail: efimov.aa @ mipt.ru \\ http://dx.doi.org/10.13005/ojc/340613
}

Received: September 20, 2018; Accepted: November 10, 2018)

\begin{abstract}
In this paper we investigated the effect of substrate temperature $\left(25-300^{\circ} \mathrm{C}\right)$ on the aspect ratio (thickness/width) of the silver lines formed by aerosol jet printing (AJP). This effect was studied by varying the speed of substrate $(50-250 \mathrm{~mm} / \mathrm{min}$.) and the number of printing layers (1-25 layers) in order to obtain lines with high aspect ratio. It is shown that AJP on a heated substrate at a temperature equal to $>100^{\circ} \mathrm{C}$ allows to increase the aspect ratio of the lines more than 17 times in comparison with conventional AJP. It is established that the aspect ratio of the lines increases with the increase in the number of printing layers and the decrease in the speed of substrate. Silver lines with high aspect ratio of 1.7 with a width of about $25 \mu \mathrm{m}$ were formed. This result is important for the formation of current-carrying microcircuits with a high density of elements.
\end{abstract}

Keywords: Aspect Ratio, Aerosol Jet Printing, Silver Ink, Printed Electronics.

\section{INTRODUCTION}

The conventional method of aerosol jet printing (AJP) is a universal method for printing electronic components on various substrates using a large selection of functional inks ${ }^{1-4}$. The AJP method is becoming more and more popular in the field of printed electronics, as it allows to create inexpensive electronic elements with a size of $10 \mu \mathrm{m}$ to several millimeters ${ }^{5-8}$. Conducting lines with a narrow width and a large cross-sectional area are preferred in printed electronics for the purpose of forming circuits with a high density of elements ${ }^{6,9}$. In this regard, the main task of researchers in the field of printed electronics is to create microstructures with high values of the aspect ratio (AR), where the $A R$ is defined as the ratio of thickness to the width of the lines ${ }^{10}$. For example, in the paper ${ }^{6}$, a technique was investigated to increase the AR of the lines by changing the parameters of the AJP method, namely, by controlling the aerosol and sheath gas flow rates. However, this technique did not significantly allow to

This is an Open Access article licensed under a Creative Commons license: Attribution 4.0 International (CC- BY). Published by Oriental Scientific Publishing Company @ 2018 
increase the AR of the lines to values greater "than $0.2^{1 "}$ In another paper ${ }^{11}$, the AR of the line increased due to the increase in the number of printing layers and the slow printing speed, but this only resulted in a slight increase in the AR of the line, because due to the spreading of the ink, both the thickness and the width of the formed lines increased.

In this paper we investigated the effect of substrate temperature $\left(25-300^{\circ} \mathrm{C}\right)$ on the values of AR of the silver lines formed by AJP on a heated substrate. This effect was studied by varying the speed of substrate $(50-250 \mathrm{~mm} / \mathrm{min}$.) and the number of printing layers (1-25 layers) in order to obtain printed lines with high aspect ratio.

\section{EXPERIMENTAL}

Figure 1 shows the scheme of the experiment setup to study the effect of the substrate temperature on the AR values of silver lines formed by AJP on a heated substrate. The experiments were performed using a commercial aerosol jet printer AJ 15XE $\left(\right.$ Neotech AMT GmbH) ${ }^{12}$. The ink used was a conductive silver ink Micro PE PG-007MOP (Paru Co., Ltd) with a mass concentration of silver nanoparticles equal to $50 \%$, dispersed in ethylene glycol ${ }^{13}$.

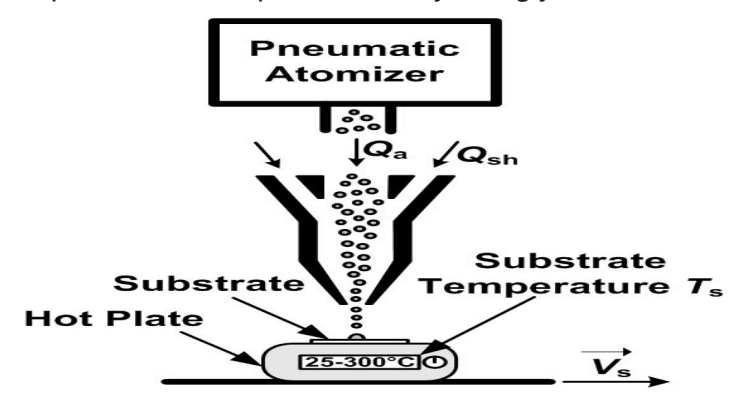

Fig. 1. Scheme of the experiment setup to study the effect of the substrate temperature on the AR values of silver lines formed by the AJP on the heated substrate, where $Q_{a}$ is the aerosol flow rate, $Q_{s h}$ is the sheath gas flow rate, $V_{s}$ is the speed of substrate, and $T_{s}$ is the substrate temperature

Aerosol particles in the form of liquid microdroplets were obtained by means of a pneumatic atomizer while spraying silver ink. Then the particles were directed to the coaxial nozzle for focusing and deposition on the heated substrate, see Fig. 1. In the experiment, a nozzle with an output diameter of $150 \mu \mathrm{m}$ was used. The distance from the nozzle to the substrate was $2 \mathrm{~mm}$. The aerosol flow rate $Q_{a}$ and the sheath gas flow rate $Q_{s h}$ were 50 and 100 sccm, respectively. Pure nitrogen $\mathrm{N}_{2}(99.9999 \%)$ was used as the carrier gas for the aerosol and sheath gas flows. The glass substrate was placed on the surface of the C-MAG HP 4 hot plate (IKA Works, Inc.), which moved relative to the nozzle at a variable speed of substrate $V_{s}$ in the range from 50 to $250 \mathrm{~mm} / \mathrm{min}$. During the experiment, the substrate temperature $T_{s}$ was controlled in the range from 25 to $300^{\circ} \mathrm{C}$. The number of printing layers $N_{p}$ varied from 1 to 25 layers. The width and the thickness of the lines for determining the AR of the line were obtained from analysis of the cross-sectional profile of the printed lines, which was measured using an optical profilometer Leica DCM 3D. As a result, a series of experiments were performed to estimate the effect of the substrate temperature on the values of the AR of the lines with a variation in the speed of the substrate and the number of printing layers.

\section{RESULT AND DISCUSSION}

Figure $2 \mathrm{a}$ shows the dependence of the $A R$ of the silver lines on the substrate temperature in the range from 25 to $300^{\circ} \mathrm{C}$ with the speed of the substrate equal to 50,125 and $250 \mathrm{~mm} / \mathrm{min}$, where $N p=25$ layers. As an example, Fig. $2 b$ also shows individual cross-section profiles of lines formed on the substrate at $T_{s}=200^{\circ} \mathrm{C}, N_{p}=25$ layers and $V_{s}$ are equal to 50,125 and $250 \mathrm{~mm} / \mathrm{min}$.

It can be seen from Fig. 2a that the values of the $A R$ of the silver lines increases linearly with increasing the substrate temperature in the range from 25 to $100^{\circ} \mathrm{C}$, and when the substrate temperature increases above $100^{\circ} \mathrm{C}$, the $A R$ of the lines did not change and become constant for all values of the speed of substrate. This result indicates that the reason for the growth of the AR of the line in the temperature range from 25 to $100^{\circ} \mathrm{C}$ is probably associated with a decrease in the degree of spreading of the ink as a result of their rapid drying and solidification on the surface of the heated substrate. As a consequence, the highest values of $A R$ of the line are reached at a substrate temperature equal to or higher than the sintering temperature of the ink. For example, the starting temperature of the sintering used by the silver ink is about $100^{\circ} \mathrm{C}$ and higher according to the ink specifications ${ }^{13}$. In Fig. 2a, it is seen in the attainment of AR of the line values for its maximum when the substrate 
temperature rises above $100^{\circ} \mathrm{C}$. In this connection, it can be concluded that in order to form the highest possible microstructures, it is recommended to use the substrate temperature at which the ink dries and solidifies completely during the deposition of the ink on the substrate. Fig. 2 a shows that the higher AR of the lines are obtained for microstructures formed at a lower speed of substrate, namely at $V s=50 \mathrm{~mm} /$

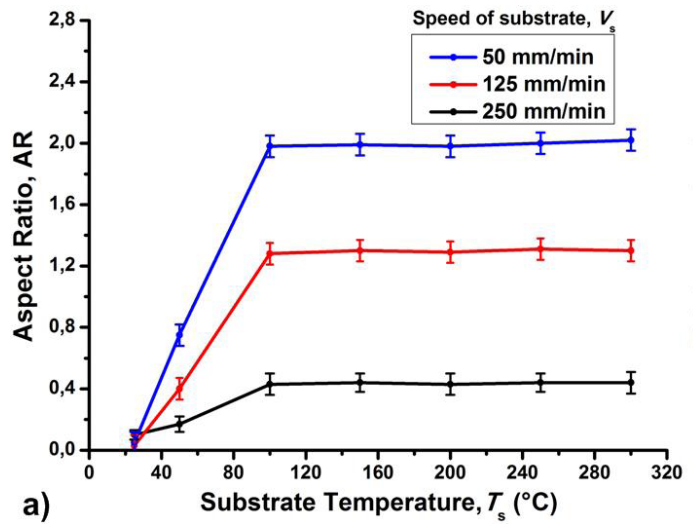

Fig. 2. a) The dependence of the $A R$ of the silver lines on the substrate temperature in the range from 25 to $300^{\circ} \mathrm{C}$ at the speed of substrate equal to 50,125 and $250 \mathrm{~mm} / \mathrm{min}$. where $N_{p}=25$ layers; b) The cross-section profiles of the lines formed on the substrate at $T_{s}=200^{\circ} \mathrm{C}, N_{p}=25$ layers and $V_{s}$ are equal to 50,125 and $250 \mathrm{~mm} / \mathrm{min}$

Figure 3 shows the dependence of the $\mathrm{AR}$ of the lines on the number of printing layers for the heated $\left(T_{s}=200^{\circ} \mathrm{C}\right)$ and unheated $\left(T_{s}=25^{\circ} \mathrm{C}\right)$ substrate at $V_{s}=125 \mathrm{~mm} / \mathrm{min}$.

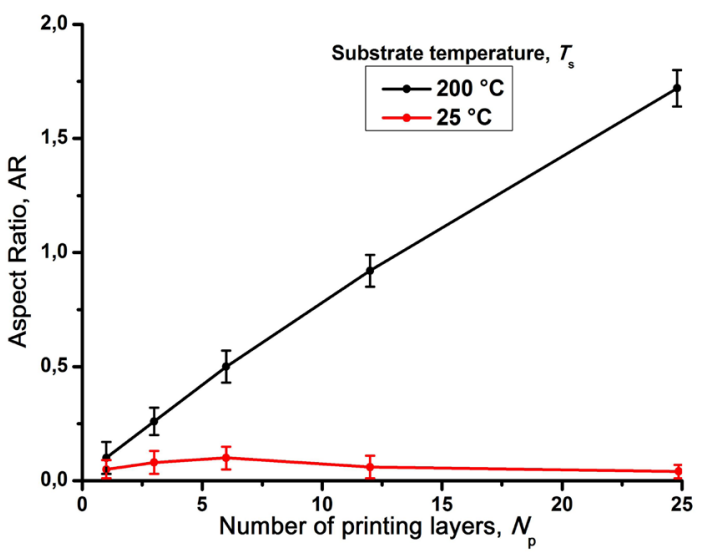

Fig. 3. The dependence of the AR of the lines on the number of printing layers for the heated $\left(T_{s}=200^{\circ} \mathrm{C}\right)$ and unheated $\left(T_{s}=25^{\circ} \mathrm{C}\right)$ substrate at $V_{s}=125 \mathrm{~mm} / \mathrm{min}$

Figure 3 shows that when the lines are printed on a heated substrate at $T s=200^{\circ} \mathrm{C}$, the $A R$ of the lines increases almost linearly with increasing number of printing layers. For example, the AR of the lines increases from 0.1 to 1.7 when the number of printing layers is increased from 1 to 25 layers, minute. However, it should also be taken into account that with a decrease in the speed of substrate from 250 to $50 \mathrm{~mm} / \mathrm{min}$. the width of the lines increases from $35 \pm 4$ to $62 \pm 6 \mu \mathrm{m}$, respectively, see Fig. $2 \mathrm{~b}$. Therefore, in order to obtain at the same time narrow lines having a large cross-sectional area, in subsequent experiments, the $V_{s}$ was chosen to be $125 \mathrm{~mm} / \mathrm{min}$.

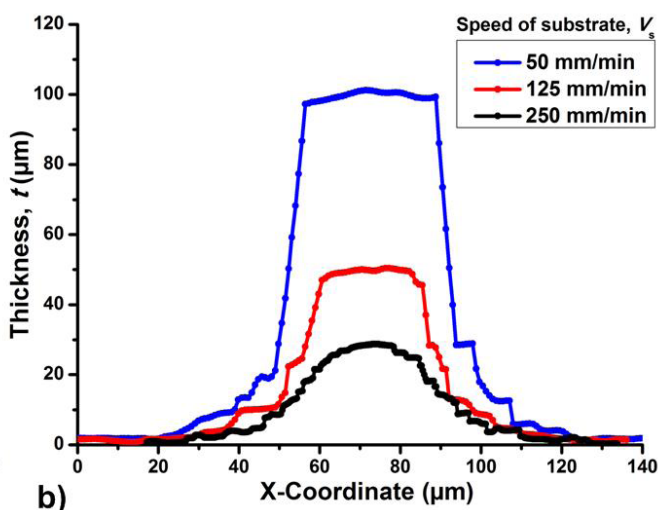

respectively. The use of a heated substrate allows increasing the AR of the line by more than 17 times in comparison with lines printed on an unheated substrate. However, when the lines printing on an unheated substrate at $T s=25^{\circ} \mathrm{C}$, the values of $A R$ of the lines remain almost unchanged with increasing number of printing layers. This indicates that when the ink is deposited on an unheated substrate, along with the increase in line thickness due to a larger amount of deposited material, its width also increases proportionally in accordance with the expression $\mathrm{AR}=$ (thickness/width). Fig. 4 clearly shows the cross-sectional profiles of the lines and their $3 \mathrm{D}$ images, depending on the number of printing layers formed at $T s=25^{\circ} \mathrm{C}$ and $V s=100 \mathrm{~mm} /$ min. Fig. 4 shows that as the number of printing layers increases, the thickness and width of the lines also increase. This is probably related to the process of spreading ink over the substrate at room temperature.

Under conditions of printing on a heated substrate, when the material is deposited on the heated surface, the ink dries and solidifies, not having time to spread, and the subsequent layer 
of the material precipitates already on the sintered surface. Fig. 5 also clearly shows the cross-sectional profiles of the lines and their 3D images, depending on the number of printing layers formed at $T s=200^{\circ} \mathrm{C}$ and $V s=100 \mathrm{~mm} / \mathrm{min}$.

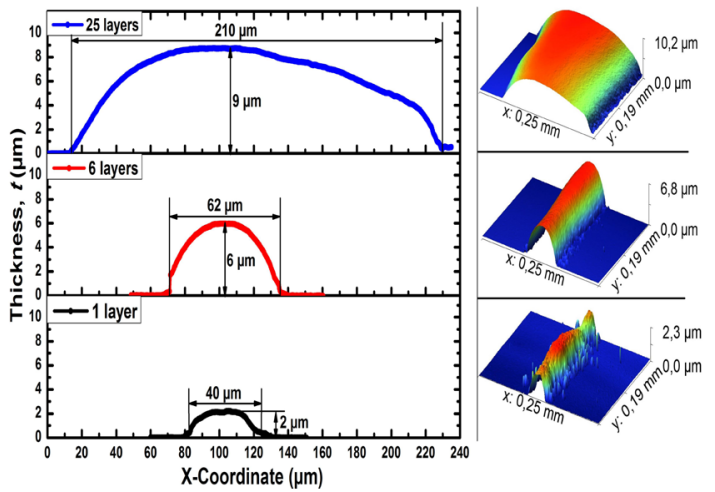

Fig. 4. The cross-sectional profiles of the lines (left) and their 3D images (right), depending on the number of printing layers formed at $T_{s}=25^{\circ} \mathrm{C}$ and $V_{s}=125 \mathrm{~mm} / \mathrm{min}$

Thus, the AJP method on a heated substrate is similar to some of the traditional methods for layered creation of 3D objects ${ }^{14}$. According to the results of the experiments, it has been established that using the AJP method on a heated substrate it is possible to form lines with a relatively high aspect ratio $A R>1$, which is relevant for the creation of electronic circuits with high element densities and is of fundamental importance in the development of new functional 3D micro devices.

\section{CONCLUSION}

The influence of the substrate temperature, the speed of substrate and the number of printing layers on the aspect ratio of the lines formed by the method of aerosol jet printing on the heated substrate is studied. It was found that with an increase in the substrate temperature in the range from 25 to $100^{\circ} \mathrm{C}$, an almost linear increase in the values of the aspect ratio of the lines from the substrate temperature is observed. In addition, it was found that the substrate heating temperature above
It can be seen from Fig. 5 that with an increase in the number of printing layers from 1 to 25 layers, the line width remains almost constant $\sim 25 \mu \mathrm{m}$, and the thickness of the line increases from 3 to $40 \mu \mathrm{m}$, respectively.

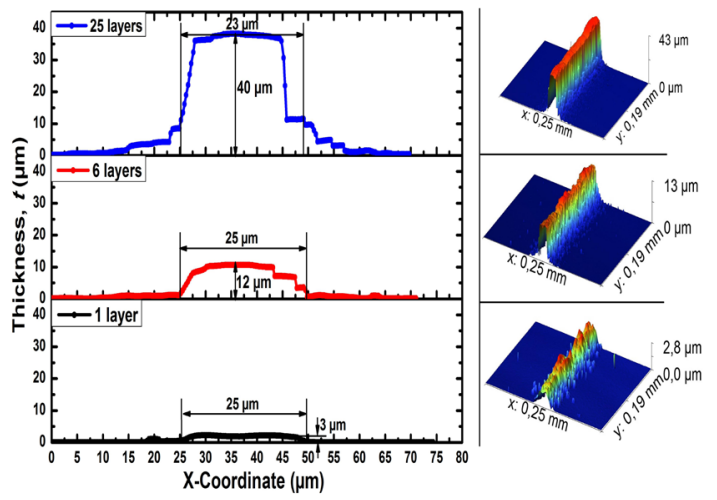

Fig. 5. The cross-sectional profiles of the lines (left) and their 3D images (right), depending on the number of printing layers formed at $T_{s}=200^{\circ} \mathrm{C}$ and $V_{s}=125 \mathrm{~mm} / \mathrm{min}$

$100^{\circ} \mathrm{C}$ practically does not affect the AR values for different speed of substrate from 50 to $250 \mathrm{~mm} / \mathrm{min}$. The result is probably due to a change in the speed of drying and solidification of the ink on the surface of the heated substrate, which reaches its maximum values and goes to constant at the temperature of complete sintering of the ink on the substrate. It has also been found that the lower the speed of substrate, the more AR of the lines can be obtained. Under the conditions of using the heated substrate to $200^{\circ} \mathrm{C}$, by varying the number of printing layers from 1 to 25 layers, the possibility of linear increase in the values of AR of the lines from 0.1 to 1.7 , respectively, and having a minimum width of about $25 \mu \mathrm{m}$ is demonstrated.

\section{ACKNOWLEDGEMENT}

This work is supported by the grant of the President of Russian Federation for young scientists MK-2302.2017.8 and carried out using the Shared Use Equipment Center for high-precision measuring in photonics (ckp.vniiofi.ru, VNIIOFI). The authors declare no conflict of interest.

\section{REFERENCES}

1. Deiner, L. J.; Reitz, T. L. Adv. Eng. Mater., 2017, 19(7), 1600878.

2. Ou, C.; Sangle, A. L.; Datta, A.; Jing, Q.; Busolo, T.; Chalklen, T.; Narayan, V.; KarNarayan, S. ACS Appl. Mater. Interfaces.
2018, 10(23), 19580-19587.

3. Kahn, B. E. Org. Print. Electron., 2007, 1(2), 14-17.

4. Eckstein, R.; Rödlmeier, T.; Glaser, T.; Valouch, S.; Mauer, R.; Lemmer, U.; Hernandez Sosa, G. Adv. Electron. Mater., 2015, 1(8), 1500101. 
5. Rahman, T.; Renaud, L.; Heo, D.; Renn, M.; Panat, R. J. Micromechanics Microengineering., 2015, 25(10), 107002.

6. Mahajan, A.; Frisbie, C. D.; Francis, L. F. ACS Appl. Mater. Interfaces., 2013, 5(11), 4856-4864.

7. Laurent, P.; Stoukatch, S.; Dupont, F.; Kraft, M. Microelectron. Eng., 2018, 197, 67-75.

8. Efimov, A.;Potapov, G.; Nisan, A.;Urazov, M.; Ivanov, V. Orient. J. Chem., 2017, 33(2), 1047-1050.

9. Suherman; Hossain, M.M.; Morita, K.; Kawaguchi, T. Orient. J. Chem., 2018, 34 (3), 1355-1361.

10. Suganuma, K. Introduction to Printed Electronics;
SpringerBriefs in Electrical and Computer Engineering; Springer-Verlag: New York, 2014.

11. Kopola, P.; Zimmermann, B.; Filipovic, A.; Schleiermacher, H.-F.; Greulich, J.; Rousu, S.; Hast, J.; Myllylä, R.; Würfel, U. Sol. Energy Mater. Sol. Cells., 2012, 107, 252-258.

12. Neotech AMT -3D Printed Electronics http://www. neotech-amt.com/ (accessed Sep 17, 2018).

13. http://paru.co.kr/ko-KR/Web/Print/Product/ Ink/ (accessed Sep 13, 2018).

14. Ligon, S.C.;Liska, R.; Stampfl, J.; Gurr, M.; Mülhaupt, R. Chem. Rev., 2017, 117(15), 10212-10290. 